\title{
Therapeutic Role of Resveratrol and Piceatannol in Disease Prevention
}

\author{
Aayush Kukreja ${ }^{1 *}$, Neha Wadhwa ${ }^{2}$ and Archana Tiwari ${ }^{1}$ \\ ${ }^{1}$ School of Biotechnology, Rajiv Gandhi Proudyogiki Vishwavidyalaya, Bhopal, India \\ ${ }^{2}$ Department of Biotechnology, College of Professional Studies, SR Group of Institutions, Bhopal, India
}

\begin{abstract}
Resveratrol, (3,4',5-trihydroxystilbene) has long been suspected to show a broad range of biological activities of medicinal interest such as anticancer, anti-oxidative, anti-diabetic, anti-aging and anti-inflammatory activities. Piceatannol $\left(3,3^{\prime}, 4^{\prime}, 5\right.$-tetrahydroxystilbene) is a hydroxylated analogue of resveratrol and it confirms a lot of similar biological activities as shown by resveratrol. Both resveratrol and piceatannol are very important naturally occurring polyphenolic stilbenes, produced by plants in response to fungal infection, mechanical damage, or ultra-violet irradiation. They can be consumed on a daily basis as they show no harmful effects on human body. They play a significant role in improving human health. Compared with resveratrol, piceatannol is a more potent anticancer agent and preferable agent with other biological activities like antioxidant activity. This article reports biological activities of the two important stilbenes: resveratrol and piceatannol and their possible role in disease prevention.
\end{abstract}

Keywords: Resveratrol; Piceatannol; Polyphenols; Biological activities

\section{Introduction}

Polyphenols are abundant micronutrients that complement and add to the functions of antioxidants, vitamins and enzymes as a defense against oxidative stress caused by excess reactive oxygen species. They contain phenolic rings in their structure and are found in different forms in nature. These compounds are classified into different groups on the basis of the number of phenol rings that they contain and structural elements that are attached to these rings (Figure 1) [1,2].

Resveratrol is the most well characterized stilbenes, having a trihydroxystilbene skeleton [3,4]. Piceatannol closely resembles resveratrol in structure [5]. Both piceatannol and resveratrol possess almost similar biological activities like antioxidant, antiproliferative and anti-inflammatory properties [6]. The importance of these compounds in disease prevention has been reviewed here.

\section{Resveratrol}

Resveratrol (3,4,5-trihydroxystilbene) is a natural stilbene containing two aromatic rings in its structure. It is a phytoalexin formed

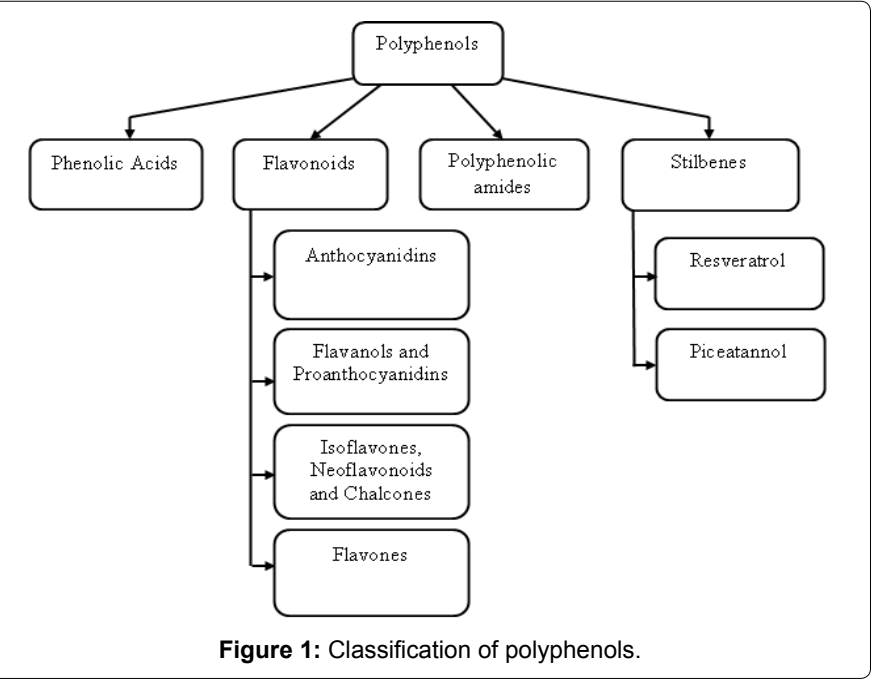

naturally by 72 different plant species, especially pine trees, jackfruit, mulberry, blueberry, cranberry, grape vines and legumes (Figure 2). It is found in large amount in peanuts, soybeans and pomegranates [7-10].

Resveratrol exists in two isomeric forms: cis-resveratrol and transresveratrol. The trans form is more stable and potent than the cis form. Molecular structure of resveratrol consists of two aromatic rings that are linked together by a methylene double bond (Figure 3) [8].

All the three hydroxyl groups of resveratrol are responsible for intensive hydrogen-bonding network [10]. Its biological activity is dependent on the presence of intramolecular hydrogen bonding, double bond and number and position of hydroxyl groups [11]. Resveratrol is a fat soluble plant secondary metabolite produced with the help of enzyme stilbene synthetase [12]. It is known to possess good cancer chemo preventive properties [10].

\section{Biological Activities of Resveratrol}

Resveratrol has many biological roles and different mechanisms of action [13]. It can inhibit the progression of several diseases, including cardiovascular disease, carcinogenic, neurodegenerative, and prevent aging process. Resveratrol has found to possess anti-inflammatory, antioxidant and antimicrobial properties $[9,13]$.

\section{Resveratrol as an antioxidant}

Recognition of resveratrol as a natural antioxidant agent was illustrated by Zini et al. [14,15]. Resveratrol possesses both antioxidant and free radical scavenging activity. It increases the activities of antioxidant enzymes such as glutathione peroxidase, SOD (superoxide

*Corresponding author: Aayush Kukreja, School of Biotechnology, Rajiv Gandhi Proudyogiki Vishwavidyalaya, Airport Road-Bhopal-462033 Madhya Pradesh, India, Tel: 0755-2678873; Fax: 0755-2742006; E-mail: aayush_kukreja@yahoo.co.in

Received September 29, 2014; Accepted November 29, 2014; Published December 05, 2014

Citation: Kukreja A, Wadhwa N, Tiwari A (2014) Therapeutic Role of Resveratrol and Piceatannol in Disease Prevention. J Blood Disorders Transf 5: 240. doi: 10.4172/2155-9864.1000240

Copyright: (c) 2014 Kukreja A, et al. This is an open-access article distributed under the terms of the Creative Commons Attribution License, which permits unrestricted use, distribution, and reproduction in any medium, provided the original author and source are credited. 


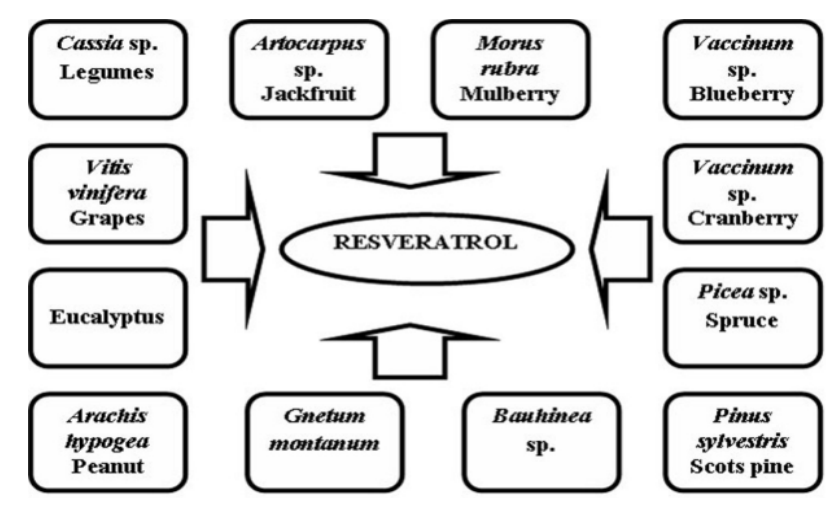

Figure 2: Sources of resveratrol.

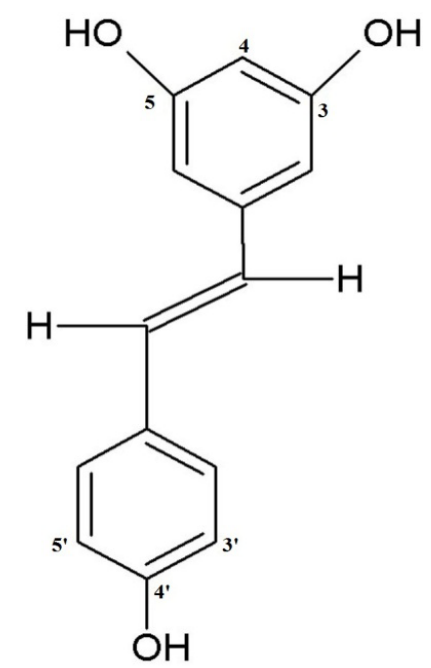

Figure 3: Chemical structure of resveratrol.

dismutase), catalase, and glutathione reductase [16]. It also maintains the level of intracellular antioxidants in the biological systems [15].

\section{Resveratrol as an anticancer agent}

Resveratrol is a good anticancer agent known since ages [11]. It inhibits onset and promotion of cancer. It promotes anti-tumoral activity by inhibiting angiogenesis $[17,18]$. The anti-cancer effect of resveratrol is associated with the damage of mitochondrial function that leads to an increase in ROS (reactive oxygen species), apoptosis and possibly intracellular drug accumulation via inhibition of proteins involved in MDR (multi-drug resistance) [19].

\section{Resveratrol as an anti-inflammatory agent}

Resveratrol exhibits anti-inflammatory activity through modulation of enzymes and pathways that are mostly centered on cyclooxygenases COX-1 and COX-2. It also suppresses the activity of NF-kB (nuclear factor kappa light chain enhancer of activated B cells) and I-kB (inhibitor of kappa) kinase and reduced production of prostaglandin E2 (PGE2) and ROS in lipopolysaccharide (LPS) -activated microglial cells $[20,21]$.

\section{Resveratrol as an anti-microbial agent}

Resveratrol possesses antimicrobial properties. It inhibits the growth of some pathogenic microorganism such as gram-positive and gram-negative bacteria and fungi like Aspergillus niger, Helicobacter pylori, Aspergillus flavus, Candida albicans, Staphylococcus aureus, Escherichia coli and Pseudomonas aeruginosa [13]. It inhibits the growth of Escherichia coli via site-specific oxidative damage to the cell membrane [14]. Resveratrol is a potent antimicrobial agent and may be used in future for the treatment of infections caused by certain pathogens $[22,23]$.

\section{Resveratrol as an anti-aging agent}

Resveratrol possesses anti-aging activity. Its anti-aging activity was seen on yeast (Saccharomyces cerevisiae), fruit fly (Drosophila melanogaster) and round worm (Caenorhabditis elegans). Resveratrol increases genetic expression of SIR2 enzyme, NAD-dependent, sirutuin class of deacetylase resulting in an increase in the life time of these species [24].

\section{Resveratrol in cardiovascular protection}

Resveratrol possesses cardioprotective effects as it inhibits platelet aggregation, thromboxane A2 formation (vasodilator effect) and peroxidase reactions of Cox-1 [25]. It has been observed that even low doses (such as consumed in the common diet) of resveratrol shows cardio-protective activity [26].

\section{Resveratrol in cancer prevention}

Resveratrol has been reported to inhibit the proliferation of tumors of breast, colon and prostate cancer. Various mechanisms for the anticancer action of resveratrol include angiogenesis inhibition, cell cycle alteration, apoptosis and antioxidant effects. It also suppresses cytochrome $\mathrm{P} 450$ that is considered as procarcinogens $[18,25]$.

\section{Resveratrol in neurological disorder}

Resveratrol is a neuroprotective supplement for neurological disorders like Alzheimer's disease, Parkinson disease and Huntingtons disease. It reduces the level of neuronal cell death. It represses p53, thereby preventing neurons from oxidative damage [25].

\section{Resveratrol in thalassemia}

Resveratrol possesses both anti-oxidant and $\mathrm{HbF}$ (fetal hemoglobin) inducing properties. It activates gamma $(\gamma)$-globin genes expression and helps in the production of $\mathrm{HbF}$. This property of resveratrol is helpful in the treatment of beta thalassemia [27].

\section{Resveratrol in diabetes}

Resveratrol has been hypothesized to protect $\beta$ cells in diabetes. It has experimentally proved that resveratrol lowers the insulin secretion in blood. Its inhibitory effect has been proved in hyperinsulinemic animals [28]. Resveratrol shields against hepatic and renal impairment in the diabetic patients [29]. This indicates that resveratrol has beneficial role in the prevention and treatment of diabetes [28].

\section{Piceatannol}

Piceatannol (3,3', ',5-tetrahydroxystilbene) is a naturally occurring hydroxylated analog of resveratrol (Figure 4). It has two phenol rings that are linked together by a styrene double bond. It exists in two isomeric forms: cis- piceatannol and trans- piceatannol. Usually, its trans isomeric form is more stable as compared to cis form $[6,30,31]$.

It has been identified in various plants specifically in passion fruit (Passiflora edulis), Cassia marginata, Melaleuca leucadendron, 


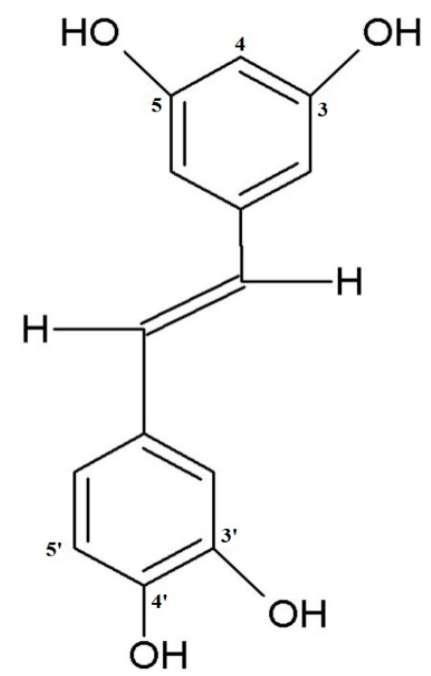

Figure 4: Chemical structure of piceatannol.

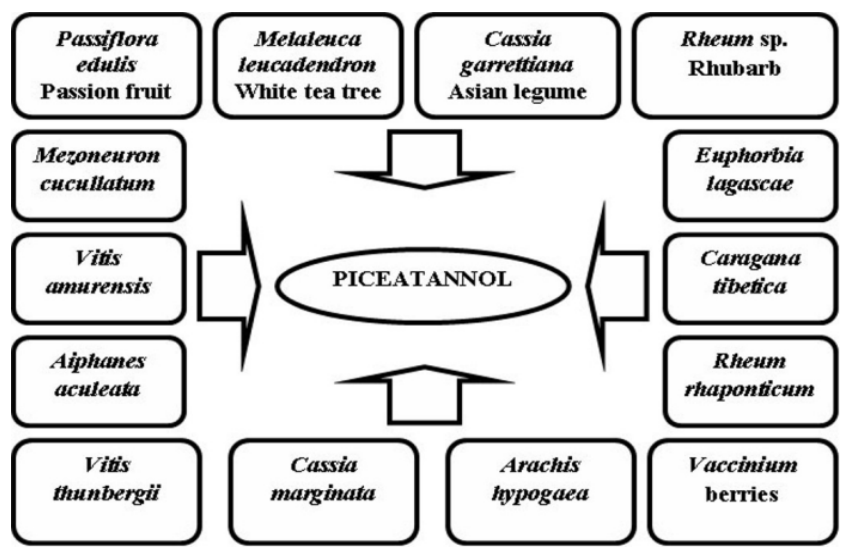

Figure 5: Sources of piceatannol.

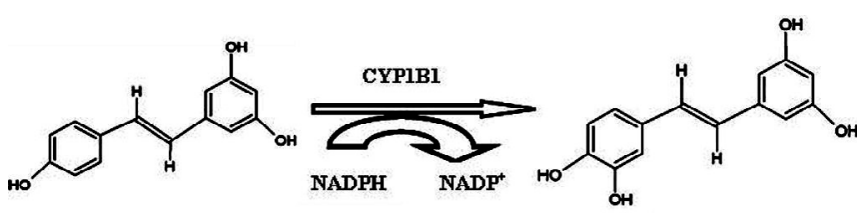

Resveratrol

Piceatannol

Figure 6: Resveratrol metabolism in humans.

Asian legume (Cassia garrettiana), Rhubarb (Rheum spp.), Euphorbia lagascae, Mezoneuron cucullatum, Vitis amurensis, Caragana tibetica, Rheum rhaponticum, Partneocissus tricuspidata, Aiphanes aculeata, Arachis hypogaea, Vitis thunbergii, Ampelopsis brevipedunculaata and Vaccinium berries (Figure 5) [6].

Rhodomyrtus tomentosa also known as Sim fruit has been reported to contain 1000-2000 times higher piceatannol than that found in red grape [32]. In humans, resveratrol metabolism in the presence of enzyme CYP1B1 (Cytochrome P450 1B1) produces piceatannol as a major metabolite (Figure 6) [8].

\section{Biological Activities of Piceatannol}

Like resveratrol, piceatannol also has many biological roles and different mechanisms of action. It possesses biological activities like anticancer, antioxidant, antileukaemic and anti-inflammatory activities. It also possesses property to combat diseases like breast cancer, prostate cancer, colon cancer, leukemia, lymphoma and melanoma [6].

\section{Piceatannol as an antioxidant agent}

The antioxidant activity of piceatannol is due to hydroxyl groups in its stilbene rings. It has good lipid peroxyl radical scavenging activity. Semiquinone radical of piceatannol is found to be more stable. Its antioxidant activity was proved by its ability to suppress the production of melanin in B16 melanoma cells $[6,33]$.

\section{Piceatannol as an anticancer agent}

Piceatannol exhibits anticancer activity due to its potential to inhibit spread of a vast array of different tumor cells, including lymphoma, leukaemia, breast cancer, prostate cancer, and colon cancer. It shows growth inhibition and the proapoptic effect on cancer cells. Its proapoptic effect may be due to loss of mitochondrial potential, activation of caspases and release of cytochrome C [6].

Its proapoptic activity has been observed in various cancer cells including skin, prostate, bladder and breast. It possesses cytotoxicity activity against prostate cancer cells. It inhibits JAK1 (Janus kinase) activity proving itself to be curative agent for prostate cancer [6]. In colon and liver cancer, piceatannol has found to be responsible for accumulation of cells in G1 and S phase of cell cycle [34]. In bladder cancer, it has been reported that piceatannol induces apoptosis and obstructs G0/G1 cells progression [35].

\section{Piceatannol as an antileukaemic agent}

Piceatannol exhibits antileukaemic activity as its treatment results in an increase in Fas and FasL protein expression. It induces death of human leukaemia cells by increasing intracellular $\mathrm{Ca} 2+$ concentration, activating p38 mitogen activated protein kinase (MAPK), inactivating extracellular regulated kinase (ERK), producing t-Bid and degrading procaspase-8 in leukaemic cells $[6,36]$.

Piceatannol results in apoptosis, DNA fragmentation, decreased Bcl-2 and cIAP-2 (anti- apoptic proteins) expression and halt of cells in sub G1 phase. Up-regulation of Fas/FasL has been reported in piceatannol treated leukaemic cells [5,37].

\section{Piceatannol as an anti-inflammatory agent}

Piceatannol shows anti-allergic inflammatory activity by regulating MAPK signaling pathway. It suppresses SyK activity by obstructing FceR I-mediated signaling in mast cells $[6,38]$.

\section{Piceatannol as an anti-adipogenic agent}

Piceatannol plays a vital role in inhibiting adipogenesis. It downregulates C/EBP and PPAR (pro-adipogenic transcription factors) expression. It also inhibits phosphorylation and kinase activity of signaling pathways including IR and PI3K/Akt pathway [39].

\section{Piceatannol as an antimelanogenic agent}

Picetannol upregulates intracellular GSH level and downregulates GSSG level in B16 cells. It increases GSH/GSSG ratio resulting in an increase in intracellular reducing power, which plays a pivotal role in the regulation of melanogenesis. It lowers melanin content without exhibiting any antagonist effect on cell viability [40]. 


\begin{tabular}{|c|c|c|}
\hline Activity & Resveratrol & Piceatannol \\
\hline Antioxidant & Present & Present \\
\hline Anti-inflammatory & Present & Present \\
\hline Anticancer & Present & Present \\
\hline Antileukaemic & Present & Present \\
\hline
\end{tabular}

Table 1: Similar biological activities of resveratrol and piceatannol [11,14$19,29,32,33,36]$

\begin{tabular}{|c|c|c|c|c|c|c|c|}
\hline \multirow{3}{*}{ Compound } & \multicolumn{7}{|c|}{ Position on the ring } \\
\cline { 2 - 9 } & & 3 & 4 & 5 & 3 & 4 & 5 \\
\cline { 2 - 9 } & Resveratrol & $\mathrm{OH}$ & - & $\mathrm{OH}$ & - & $\mathrm{OH}$ & - \\
\cline { 2 - 9 } & Piceatannol & $\mathrm{OH}$ & - & $\mathrm{OH}$ & $\mathrm{OH}$ & $\mathrm{OH}$ & - \\
\hline
\end{tabular}

Table 2: Table showing hydroxyl group positions in resveratrol and piceatannol [6].

\begin{tabular}{|c|c|c|}
\hline Parameters & Piceatannol & Resveratrol \\
\hline Nomenclature & $\begin{array}{l}\text { 3,3',4',5-trans- } \\
\text { trihydroxystilbene }\end{array}$ & $\begin{array}{l}\text { 3,4',5-trans- } \\
\text { trihydroxystilbene }\end{array}$ \\
\hline $\begin{array}{l}\text { Spectrophotometric } \\
\text { analysis in ethanol }\end{array}$ & $\begin{array}{l}\text { Absorbs maximally at } \\
322 \mathrm{~nm}\end{array}$ & $\begin{array}{l}\text { Absorbs maximally at } \\
308 \mathrm{~nm} \text {. }\end{array}$ \\
\hline Content in grapes & $\begin{array}{c}\text { About 4-times lower than } \\
\text { resveratrol }\end{array}$ & $\begin{array}{l}\text { about } 4 \text {-times higher } \\
\text { than piceatannol }\end{array}$ \\
\hline Inhibitory activity & $\begin{array}{l}\text { Does not inhibit CYP2E1 } \\
\text { (Cytochrome P450 2E1) }\end{array}$ & $\begin{array}{c}\text { Inhibits CYP2E1 } \\
\text { (Cytochrome P450 2E1) }\end{array}$ \\
\hline Scavenging activity & $\begin{array}{l}\text { Show stronger activity to } \\
\text { scavenge free radicals. } \\
\text { Higher rate constant of } \\
\text { reaction with linoleate } \\
\text { (LOO•) } \\
\text { Concentration of } \\
\text { piceatannol required to } \\
\text { scavenge } \mathrm{O}_{2}^{--} \text {is } 1200 \\
\text { times lower than that of } \\
\text { Resveratrol }\end{array}$ & $\begin{array}{l}\text { Lower rate constant of } \\
\text { reaction with linoleate } \\
\qquad(\mathrm{LOO} \cdot)\end{array}$ \\
\hline $\begin{array}{c}\text { Substrate of } \\
\text { enzyme catechol-O- } \\
\text { methyltransferase } \\
\text { (COMT) }\end{array}$ & $\begin{array}{c}\text { Substrate of } \\
\text { enzyme catechol-O- } \\
\text { methyltransferase (COMT) } \\
\text { due to presence of extra } \\
\text { 3'-OH group }\end{array}$ & $\begin{array}{l}\text { Not a substrate of } \\
\text { enzyme catechol-O- } \\
\text { methyltransferase } \\
\text { (COMT) }\end{array}$ \\
\hline $\begin{array}{c}\text { Inhibition of MRP1- } \\
\text { mediated transport of } \\
\text { 2',7'--bis-(carboxypropyl)- } \\
5(6) \text {-carboxyfluorescein } \\
\text { (BCPCF) from } \\
\text { human erythrocytes }\end{array}$ & Show moderate activity & Ineffective \\
\hline Hormetic effect & $\begin{array}{l}\text { Piceatannol-induced } \\
\text { hormetic response has } \\
\text { been reported }\end{array}$ & Not reported till now \\
\hline $\begin{array}{l}\text { TPA-induced NFkB DNA } \\
\text { binding }\end{array}$ & $\begin{array}{c}\text { Inhibits NFkB DNA binding } \\
\text { to a greater extent }\end{array}$ & $\begin{array}{c}\text { inhibits NFkB DNA } \\
\text { binding to a lesser extent }\end{array}$ \\
\hline
\end{tabular}

Table 3: Table showing distinction between piceatannol and resveratrol $[6,15,18,25]$.

\section{Piceatannol in diabetes}

Piceatannol exhibits antidiabetic phytochemical activity. It enhances glucose uptake, AMPK phosphorylation and glucose transporter 4 (GLUT4) translocation to overcome insulin resistance in diabetic cells. Therefore, it plays a therapeutic role in the prevention of type 2 diabetes $[6,41]$.

\section{Piceatannol in asthma}

Piceatannol, a Syk-selective tyrosine kinase possesses significant inhibitory effect in the release of histamine and peptidoleukotriene from sensitized lung fragments. Syk kinase is an essential upstream signaling molecule which activates various inflammatory cells like $\mathrm{T}$ cells, B cells and monocytes. Its inhibition in inflammatory cell may prove to be beneficial in the treatment of asthma $[42,43]$.

\section{Piceatannol in bone formation}

Piceatannol induces differentiation of osteoblasts from its progenitor stage to well differentiated osteoblasts. It induces BMP-2 (bone morphogenetic protein-2) expression which increases alkaline phosphatase and osteocalcin production in the cells. Piceatannol stimulates BMP2-BMP receptor interaction which is linked with the production of BMP-2. Therefore, piceatannol may be useful in stimulating osteoblastic activity, which results in bone formation [44].

\section{Biological spectrum of piceatannol and resveratrol}

Piceatannol and resveratrol both belong to stilbene family. They both can be synthesized by using Perkin's approach, using 3,5-dihydoxyacetophenone as a starting material [45]. They share almost same biological activities such as antioxidant, anti-inflammatory, anticancer and antileukaemic activities (Table 1) [6].

\section{Piceatannol in Alzheimer}

Alzheimer's disease is prevalent neurodegenerative disease in the elderly people, which eventually lead to death of person suffering from this disease. Studies have shown a relationship between the consumption of polyphenol rich foods or drinks and the prevention of Alzheimer's disease. The results of a recent study provides evidence that piceatannol have high potential to prevent Alzheimer's disease [46].

\section{Piceatannol in Cardiovascular Diseases}

The frequency of cardiovascular diseases is high in developing and developed countries. Cardiovascular diseases are responsible for high rate of mortality. Many drugs are available for treating cardiovascular diseases and complications associated with it. Intake of functional foods or dietary supplements for treating cardiovascular diseases has gained wide acceptance by the general public. Piceatannol is believed to be effective in preventing cardiovascular diseases such as arrhythmia, hypercholesterolemia, angiogenesis and atherosclerosis [47].

Pretreatment with piceatannol suppresses cardiac hypertrophy which has been assessed by expression level of hypertrophy markers, cross-sectional area and heart weight/body weight ratio. It also inhibits cardiac hypertrophy induced by lentiviral GATA-6 [48].

\section{Piceatannol in reducing toxic effect of neutrophils}

Piceatannol has ability to reduce the toxic effect produced by neutrophils. It elevates the percentage of early apoptotic neutrophils and hinders the activity of protein kinase $\mathrm{C}$ which is the main regulatory enzyme in neutrophils. The result indicates that piceatannol may be used as a complementary medicine in lowering the level of activated neutrophils [49].

\section{Comparative Biological Properties of Piceatannol and Resveratrol}

Piceatannol is a more active resveratrol analogue due to the presence of additional hydroxyl group at 3' position (Table 2). It possesses stronger anticancer activity than resveratrol [6]. Piceatannol possesses higher ability to scavenge free radicals as compared to resveratrol [50]. The presence of an extra hydroxyl group in piceatannol makes it reactive and more potent antioxidant as compared to resveratrol. The required concentration of piceatannol to scavenge free radicals is 1200 times lesser than that of resveratrol [6].

Although, resveratrol possesses several beneficial effects on human health as well as in preclusion of many chronic diseases, but its low 
bioavailability and rapid metabolism limits its use in the preclusion of chronic diseases [8]. Table 3 illustrates dissimilarity between resveratrol and piceatannol.

Piceatannol has much more effective biological activity and bioavailability as compared to resveratrol. Therefore, piceatannol is gaining more scientific attention than resveratrol for improving health related diseases. But more studies are needed to prove its effective diseases saving properties $[8,38]$.

\section{Conclusions}

Resveratrol and piceatannol are naturally occurring polyphenolic compounds with a wide range of biological activities. Resveratrol plays a significant role in prevention of diseases, but due to its fast metabolism in the body and poor bioavailability, it is less preferred. Piceatannol being a natural analogue of resveratrol, contains additional hydroxyl group which confers to its more effective biological activities as compared to resveratrol. In order to make both of these compounds applicable for clinical use, they should be studied more extensively to understand their bioavailability, metabolic pathways and toxicity in humans.

\section{References}

1. Tsao R (2010) Chemistry and biochemistry of dietary polyphenols. Nutrients 2: $1231-1246$.

2. Manach C, Scalbert A, Morand C, Rémésy C, Jiménez L (2004) Polyphenols: food sources and bioavailability. Am J Clin Nutr 79: 727-747.

3. Han X, Shen T, Lou H (2007) Dietary Polyphenols and Their Biological Significance. Int J Mol Sci. 8: 950-88.

4. Bavaresco L, Fregoni M, Trevisan M, Mattivi F, Vrhovsek U, et al. (2002) The occurrence of the stilbene piceatannol in grapes. Vitis 41: 133-136.

5. Potter GA, Patterson LH, Wanogho E, Perry PJ, Butler PC, et al. (2002) The cancer preventative agent resveratrol is converted to the anticancer agent piceatannol by the cytochrome P450 enzyme CYP1B1. Br J Cancer. 86: 774778

6. Piotrowska H, Kucinska M, Murias M (2012) Biological activity of piceatannol: leaving the shadow of resveratrol. Mutat Res 750: 60-82.

7. Kukreja A, Wadhwa N, Tiwari A (2013) Therapeutic role of natural agents in beta-thalassemia: A review. Journal of Pharmacy Research 6: 954-959.

8. Catalgol B, Batirel S, Taga Y, Ozer NK (2012) Resveratrol: French paradox revisited. Front Pharmacol 3: 141

9. Baur JA, Sinclair DA (2006) Therapeutic potential of resveratrol: the in vivo evidence. Nat Rev Drug Discov 5: 493-506.

10. Drábiková K, Perečko T, Nosál' R, Harmatha J, Smidrkal J, et al. (2012) Polyphenol derivatives - potential regulators of neutrophil activity. Interdiscip Toxicol 5: $65-70$

11. Ovesná Z, Horváthová-Kozics K (2005) Structure-activity relationship of transresveratrol and its analogues. Neoplasma 52: 450-455

12. Kumar DS, Shankar P, Rao GU (2009) Health benefits of resveratrol. International Journal of Pharmaceutical Sciences and Nanotechnology 2: 407412

13. Paulo L, Oleastro M, Gallardo E, Queiroz JA (2011) Domingues. Antimicrobial properties of resveratrol: a review, (3rd Edn.) Formatex, pp: 1225-35.

14. Subramanian M, Goswami M, Chakraborty S, Jawali N (2014) Resveratro induced inhibition of Escherichia coli proceeds via membrane oxidation and independent of diffusible reactive oxygen species generation. Redox Biology 2: 865-872.

15. Bonda C, Zhang J, Pavlovic A (2011) The photostability and photostabilization of trans-resveratrol. Cosmetics and Toiletries magazine 126: 652.

16. de la Lastra CA, Villegas I (2007) Resveratrol as an antioxidant and pro-oxidan agent: mechanisms and clinical implications. Biochem Soc Trans 35: 11561160
17. De la Lastra CA, Villegas I, Martin AR (2006) Resveratrol as an antioxidant In Aggarwal BB, Shishodia S eds. Resveratrol in health and disease. Washington D.C: CRC Press: 33-56.

18. Aluyen JK, Ton QN, Tran T, Yang AE, Gottlieb HB, et al. (2012) Resveratrol: potential as anticancer agent. J Diet Suppl 9: 45-56.

19. Signorelli $P$, Ghidoni R (2005) Resveratrol as an anticancer nutrient: molecular basis, open questions and promises. J Nutr Biochem 16: 449-466.

20. Sun W, Wang W, Kim J, Keng P, Yang S, et al. (2008) Anti-cancer effect of resveratrol is associated with induction of apoptosis via a mitochondrial pathway alignment. Adv Exp Med Biol 614: 179-186.

21. Udenigwe CC, Ramprasath VR, Aluko RE, Jones PJ (2008) Potential of resveratrol in anticancer and anti-inflammatory therapy. Nutr Rev 66: 445-454.

22. Kundu JK, Shin YK, Kim SH, Surh YJ (2006) Resveratrol inhibits phorbol esterinduced expression of COX-2 and activation of NF-kappaB in mouse skin by blocking IkappaB kinase activity. Carcinogenesis 27: 1465-1474.

23. Chan MM (2002) Antimicrobial effect of resveratrol on dermatophytes and bacterial pathogens of the skin. Biochem Pharmacol 63: 99-104.

24. (2010) Resveratrol. Monograph. Altern Med Rev 15: 152-158.

25. Markus MA, Morris BJ (2008) Resveratrol in prevention and treatment of common clinical conditions of aging. Clin Interv Aging 3: 331-339.

26. Kim DH, Ahn T, Jung HC, Pan JG, Yun CH (2009) Generation of the human metabolite piceatannol from the anticancer-preventive agent resveratrol by bacterial cytochrome P450 BM3. Drug Metab Dispos. 37: 932-936.

27. Fibach E, Prus E, Bianchi N, Zuccato C, Breveglieri G, et al. (2012) Resveratrol: Antioxidant activity and induction of fetal hemoglobin in erythroid cells from normal donors and $\hat{i}^{2}$-thalassemia patients. Int J Mol Med 29: 974-982.

28. Szkudelski T, Szkudelska K (2011) Anti-diabetic effects of resveratrol. Ann N Y Acad Sci 1215: 34-39.

29. Schmatz R, Perreira LB, Stefanello N, Mazzanti C, Spanevello R, et al. (2012) Effects of resveratrol on biomarkers of oxidative stress and on the activity of delta aminolevulinic acid dehydratase in liver and kidney of streptozotocininduced diabetic rats. Biochimie 94: 374-383.

30. Kukreja A, Mishra A, Tiwari A (2013) Source, production and biological activities of piceatannol: a review. IJPSR. 4: 1000-1007.

31. Wolter F, Clausnitzer A, Akoglu B, Stein J (2002) Piceatannol, a natural analog of resveratrol, inhibits progression through the $S$ phase of the cell cycle in colorectal cancer cell lines. J Nutr 132: 298-302.

32. Lai TN, Herent MF, Quetin-Leclercq J, Nguyen TB, Rogez H, et al. (2013) Piceatannol, a potent bioactive stilbene, as major phenolic component in Rhodomyrtus tomentosa. Food Chem 138: 1421-1430.

33. Wittgen HG, van Kempen LC (2007) Reactive oxygen species in melanoma and its therapeutic implications. Melanoma Res 17: 400-409.

34. Wolter F, Clausnitzer A, Akoglu B, Stein J (2002) Piceatannol, a natural analog of resveratrol, inhibits progression through the $S$ phase of the cell cycle in colorectal cancer cell lines. J Nutr 132: 298-302.

35. Kuo PL, Hus YL (2008) The grape and wine constituent piceatannol inhibits proliferation of human bladder cancer cells via blocking cell cycle progression and inducing as/membrane bound Fas ligand-mediated apoptotic pathway. Mo Nutr Food Res. 52: 408-418.

36. Liu WH, Chang LS (2010) Piceatannol induces Fas and FasL up-regulation in human leukemia U937 cells via Ca2+/p38alpha MAPK-mediated activation of C-Jun and ATF-2 pathways. Int J Biochem Cell Biol 42: 1498-1506.

37. Kim YH, Park C, Lee JO, Kim GY, Lee WH, et al. (2008) Induction of apoptosis by piceatannol in human leukemic U937 cells through down-regulation of Bcl-2 and activation of caspases. Oncol Rep 19: 961-967.

38. Ko YJ, Kim HH, Kim EJ, Katakura Y, Lee WS, et al. (2013) Piceatannol inhibits mast cell-mediated allergic inflammation. Int J Mol Med 31: 951-958.

39. Kwon JY, Seo SG, Heo YS, Yue S, Cheng JX, et al. (2012) Piceatannol, natura polyphenolic stilbene, inhibits adipogenesis via modulation of mitotic clonal expansion and insulin receptor-dependent insulin signaling in early phase of differentiation. J Biol Chem. 287: 11566-78.

40. Yokozawa T, Kim YJ (2007) Piceatannol inhibits melanogenesis by its antioxidative actions. Biol Pharm Bull 30: 2007-2011. 
Citation: Kukreja A, Wadhwa N, Tiwari A (2014) Therapeutic Role of Resveratrol and Piceatannol in Disease Prevention. J Blood Disorders Transf 5: 240. doi: 10.4172/2155-9864.1000240

41. Minakawa M, Miura Y, Yagasaki K (2012) Piceatannol, a resveratrol derivative, promotes glucose uptake through glucose transporter 4 translocation to plasma membrane in L6 myocytes and suppresses blood glucose levels in type 2 diabetic model db/db mice. Biochem. Biophys. Res. 422: 469-75.

42. Dustin ML, Chan AC (2000) Signaling takes shape in the immune system. Cell 103: 283-294.

43. Seow CJ, Chue SC, Wong WS (2002) Piceatannol, a Syk-selective tyrosine kinase inhibitor, attenuated antigen challenge of guinea pig airways in vitro. Eur J Pharmacol 443: 189-196.

44. Chang JK, Hsu YL, Teng IC, Kuo PL (2006) Piceatannol stimulates osteoblast differentiation that may be mediated by increased bone morphogenetic protein-2 production. Eur J Pharmacol 551: 1-9.

45. Sun HY, Xiao CF, Cai YC, Chen Y, Wei W, et al. (2010) Efficient synthesis of natural polyphenolic stilbenes: resveratrol, piceatannol and oxyresveratrol. Chem Pharm Bull (Tokyo) 58: 1492-1496.
46. Hassaan $Y$, Handoussa $H$, El-Khatib AH, Linscheid MW, El Sayed N, et al. (2014) Evaluation of plant phenolic metabolites as a source of Alzheimer's drug leads. Biomed Res Int 2014: 843263.

47. Tang YL, Chan SW (2014)A review of the pharmacological effects of piceatanno on cardiovascular diseases. Phytother Res 28: 1581-1588.

48. Kee HJ, Park S, Kang W, Lim KS, Kim JH, et al. (2014) Piceatannol attenuates cardiac hypertrophy in an animal model through regulation of the expression and binding of the transcription factor GATA binding factor 6 . FEBS Lett 588 : 1529-1536.

49. Maraldi T, Vauzour D, Angeloni C (2014) Dietary Polyphenols and Their Effects on Cell Biochemistry and Pathophysiology. Oxidative medicine and cellular longevity.

50. Rhayem $Y$, Thérond $P$, Camont $L$, Couturier $M$, Beaudeux JL, et al (2008) Chain-breaking activity of resveratrol and piceatannol in a linoleate micellar model. Chem Phys Lipids 155: 48-56. 